University of Nebraska - Lincoln

DigitalCommons@University of Nebraska - Lincoln

2006

\title{
Solution Properties of 1,3-Cyclohexadiene Polymers by Laser Light Scattering and Small-Angle Neutron Scattering
}

Seok I. Yun

Ken Terao

Kunlun Hong

Yuri B. Melnichenko

George D. Wignall

See next page for additional authors

Follow this and additional works at: https://digitalcommons.unl.edu/usdoepub

Part of the Bioresource and Agricultural Engineering Commons

Yun, Seok I.; Terao, Ken; Hong, Kunlun; Melnichenko, Yuri B.; Wignall, George D.; Mays, Jimmy W.; and Britt, Phillip F., "Solution Properties of 1,3-Cyclohexadiene Polymers by Laser Light Scattering and Small-Angle Neutron Scattering" (2006). US Department of Energy Publications. 55.

https://digitalcommons.unl.edu/usdoepub/55

This Article is brought to you for free and open access by the U.S. Department of Energy at DigitalCommons@University of Nebraska - Lincoln. It has been accepted for inclusion in US Department of Energy Publications by an authorized administrator of DigitalCommons@University of Nebraska - Lincoln. 


\section{Authors}

Seok I. Yun, Ken Terao, Kunlun Hong, Yuri B. Melnichenko, George D. Wignall, Jimmy W. Mays, and Phillip F. Britt 


\section{Solution Properties of 1,3-Cyclohexadiene Polymers by Laser Light Scattering and Small-Angle Neutron Scattering}

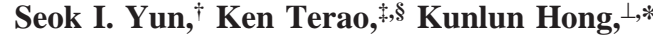 \\ Yuri B. Melnichenko, ${ }^{\dagger}$ George D. Wignall,,,$\dagger$ \\ Phillip F. Britt, ${ }^{\perp}$ and Jimmy W. Mays ${ }^{\perp, \hbar}$
}

Condensed Matter Science Division, Oak Ridge National Laboratory, Oak Ridge, Tennessee 37831; Department of Chemistry, University of Tennessee,

Knoxville, Tennessee 37996; Department of Macromolecular Science, Osaka University, 1-1 Machikaneyama-cho, Toyonaka, 560-0043, Japan; and Chemical Sciences Division and Center for Nanophase Materials Sciences, Oak Ridge National Laboratory, Oak Ridge, Tennessee 37831

Received September 16, 2005

Revised Manuscript Received October 24, 2005

\section{Introduction}

1,3-Cyclohexdiene polymers (PCHD) and their derivatives are of interest due to the six-member rings in the main chain, which are expected to impart higher mechanical strength and better thermal and chemical stability, as compared to common vinyl polymers. ${ }^{1}$ For example, hydrogenated PCHD has the highest glass transition temperature $\left(T_{\mathrm{g}} \sim 231{ }^{\circ} \mathrm{C}\right)$ of all hydrocarbon polymers, and it also shows good heat, weather, impact, abrasion, and chemical resistance as well as low water absorption. ${ }^{1}$ In addition, PCHD has unique photochemical properties, such as excellent transparency, due to the isolated double bonds in the main chain. ${ }^{2,3}$ Also, block copolymers containing PCHD show unusual phase separation behavior. For example, a styrene/1,3-CHD block copolymer (PS- $b$-PCHD) with 50 vol \% CHD $(1,4 / 1,2 \sim 95 / 5)$ exhibits a core-shell or hollow cylinder morphology, while a typical styrene/acyclic diene (isoprene or butadiene) block copolymer with similar composition exhibits a lamellar structure. ${ }^{4}$ Such phase behavior and many other properties strongly depend on the conformation of the polymer in solution or bulk. ${ }^{5}$ However, almost no data have been reported on the conformation of PCHD, probably because of the lack of well-defined and well-characterized samples. Here we report solution properties of PCHD in tetrahydrofuran (THF) and chloroform by multiangle laser light scattering, viscometry, and small-angle neutron scattering (SANS).

\section{Experimental Section}

Well-defined PCHD samples with different molecular weights and similar microstructures $(1,4 / 1,2 \sim 94 / 6)$ were prepared according to literature procedures. ${ }^{6}$ Light scattering was performed in THF on a Wyatt DAWN EOS instrument over an angular range from $38^{\circ}$ to $147^{\circ}$ using laser light at $690 \mathrm{~nm}$. The specific refractive index increments $(\mathrm{d} n / \mathrm{d} c)$ of PCHD in THF at 40 and $50{ }^{\circ} \mathrm{C}$ were determined to be 0.171 and $0.174 \mathrm{~mL} / \mathrm{g}$, respectively, using an OPTILAB DSP refractometer $(690 \mathrm{~nm})$. Intrinsic viscosities $([\eta])$ of PCHDs were measured in THF at 40 and $50{ }^{\circ} \mathrm{C}$ and also in chloroform at $40{ }^{\circ} \mathrm{C}$ using a Polymer Laboratories PL-120 size

\footnotetext{
Condensed Matter Science Division, ORNL.

$\doteqdot$ University of Tennessee.

$\S$ Osaka University.

${ }^{\perp}$ Chemical Sciences Division and Center for Nanophase Materials Sciences, ORNL.
}

exclusion chromatography (SEC) system equipped with a capillary differential viscometer (Viscotek) and a refractive index (RI) detector. Radii of gyration $\left(R_{\mathrm{g}}\right)$ were measured by using the PL120 SEC-equipped with a two-angle $\left(15^{\circ}\right.$ and $\left.90^{\circ}\right)$ light scattering photometer (PD2020) and a RI detector in THF at $40{ }^{\circ} \mathrm{C}$. Two PL-gel $10 \mathrm{~mm}$ MIXED-B columns were used with a flow rate of $1 \mathrm{~mL} \mathrm{~min}^{-1}$. A polystyrene standard $(50 \mathrm{~K})$ was used to calibrate the $90^{\circ}$ detector.

Small-angle neutron scattering (SANS) measurements were carried out on the NG3 30 m instrument $^{7}$ at the National Institute of Standards and Technology (NIST) Gaithersburg, MD, and also on the SANS- 1 facility $^{8}$ at the Paul Scherrer Institute (PSI), Villigen, Switzerland. The neutron wavelength $(\lambda)$ was $0.6 \mathrm{~nm}$ at both facilities, and the sample-detector distances were $2 \mathrm{~m}$ (NIST) and $4.5 \mathrm{~m}$ (PSI). The data were corrected for instrumental backgrounds and the (minimal) parasitic scattering from the quartz cells that contained the solutions. Corrections were also applied for the variation of the detector efficiency on a cell-by-cell basis, prior to radial averaging to give an overall range of momentum transfer $0.19<Q<3.00 \mathrm{~nm}^{-1}$ (NIST) and $0.15<Q<1.80 \mathrm{~nm}^{-1}$ (PSI), where $Q=4 \pi \lambda^{-1} \sin \theta$ and $2 \theta$ is the angle of scatter. The net intensities were converted to an absolute differential cross section per unit sample volume $\left[\mathrm{d} \Sigma(\mathrm{Q}) / \mathrm{d} \Omega\right.$ in units of $\left.\mathrm{cm}^{-1}\right]$, as previously described. ${ }^{9,10}$ Procedures for calculating the incoherent background, arising largely from the protons in the sample, have been described previously. ${ }^{11}$ The SANS cross section was measured as a function of polymer concentration, temperature, and solvent quality.

\section{Results and Discussion}

Intrinsic Viscosities. The molecular weight dependence of $[\eta]$ for PCHD in THF and chloroform is shown in Figure 1. The straight lines fitting our data for PCHD are expressed by

$$
\begin{gathered}
{[\eta]=0.12 M_{\mathrm{w}}{ }^{0.52}\left(\mathrm{~cm}^{3} \mathrm{~g}^{-1} \text { in THF at } 40{ }^{\circ} \mathrm{C}\right)} \\
{[\eta]=0.059 M_{\mathrm{w}}{ }^{0.63}\left(\mathrm{~cm}^{3} \mathrm{~g}^{-1} \text { in chloroform at } 40{ }^{\circ} \mathrm{C}\right)}
\end{gathered}
$$

The small exponents of 0.52 and 0.63 indicate that this polymer has a flexible conformation in solution. The $[\eta]$ of a wormlike chain is calculated for the touched-bead wormlike chain model by ${ }^{12}$

$$
[\eta]=f(\lambda L, \lambda d) /\left(\lambda^{3} M\right)
$$

where $L, \lambda^{-1}$, and $d_{\mathrm{B}}$ are the contour length, the Kuhn segment length, and the diameter of a bead, respectively. The first parameter is related to the molecular weight $M$ by $L=M / M_{L}$, with $M_{L}$ being the molar mass per unit contour length of the polymer chain. The contour length $L$ per monomer unit for the polymer consisting of the1,4-isomer was estimated to be 0.41 $\pm 0.03 \mathrm{~nm}$, and $M_{L}$ can be calculated to be $200 \pm 15 \mathrm{~nm}$. We note that in principle the three parameters should be determined by fitting $[\eta]$ as a function of $M$; however, the fitting is not possible because of the low exponent of $[\eta]$ vs $M_{\mathrm{w}}$. From curvefitting procedures, $\lambda^{-1}$ and $d_{\mathrm{B}}$ values were determined to be $\lambda^{-1}=1.8_{5} \pm 0.1_{5} \mathrm{~nm}$ and $d_{\mathrm{B}}=0.5_{3} \pm 0.0_{7} \mathrm{~nm}$ in chloroform and $\lambda^{-1}=1.3_{0} \pm 0.1 \mathrm{~nm}$ and $d_{\mathrm{B}}=0.5_{7} \pm 0.0_{6} \mathrm{~nm}$ in THF. The Kuhn segment length thus obtained is close to that of typical flexible polymers (e.g., polystyrene, $\lambda^{-1}=2 \mathrm{~nm}$ ). ${ }^{13}$ On the other hand, the $d_{\mathrm{B}}$ value of about $0.6 \mathrm{~nm}$ is smaller than that of polystyrene $\left(d_{\mathrm{B}} \sim 1.0 \mathrm{~nm}\right)^{14}$ or poly $(n$-hexyl isocyanate $)\left(d_{\mathrm{B}} \sim 1.6\right.$ $\mathrm{nm}),{ }^{15}$ with bulky side groups, but identical to the $0.6 \mathrm{~nm}$ value for polyisobutylene ${ }^{16}$ with small side groups. $R_{\mathrm{g}}$ for PCHD-1 


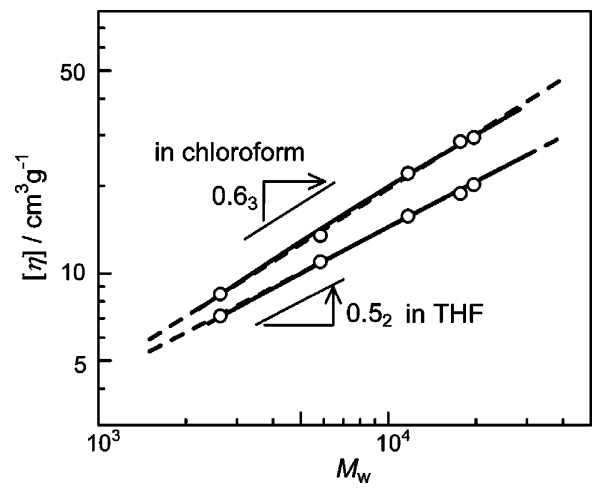

Figure 1. Molecular weight dependence of $[\eta]$ for PCHD in indicated solvents at $40{ }^{\circ} \mathrm{C}(\mathrm{THF})$ and $50{ }^{\circ} \mathrm{C}\left(\mathrm{CHCl}_{3}\right)$. Dashed lines: calculated by eq 1 . Solid curves: theoretical values for the touched-bead wormlike chain model with $M_{L}=200 \mathrm{~nm}^{-1}, \lambda^{-1}=1.8_{5} \mathrm{~nm}, d_{\mathrm{B}}=0.5_{3} \mathrm{~nm}$ (in chloroform) and $M_{L}=200 \mathrm{~nm}^{-1}, \lambda^{-1}=1.3_{0} \mathrm{~nm}, d_{\mathrm{B}}=0.5_{7} \mathrm{~nm}$ (THF).

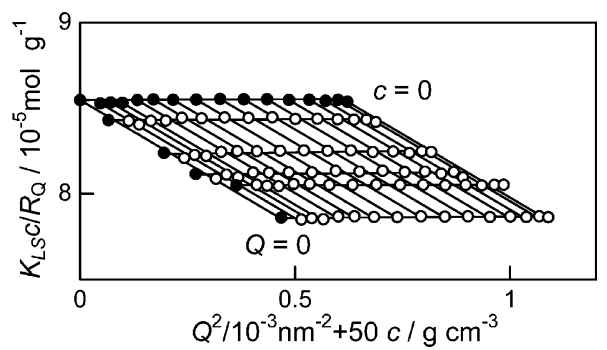

Figure 2. Zimm plot for PCHD-3 $\left(M_{\mathrm{n}}=11.7 \mathrm{~kg} / \mathrm{mol}\right.$, PDI $\left.=1.04\right)$ in THF at $40{ }^{\circ} \mathrm{C}$.

Table 1. $[\eta]$ and $M_{\mathrm{w}}$ from SEC On-Line with Two-Angle Light Scattering and Viscometry for PCHDs in THF and Chloroform

\begin{tabular}{|c|c|c|c|c|}
\hline \multirow[b]{3}{*}{ sample } & \multicolumn{3}{|c|}{ THF } & \multirow{3}{*}{$\frac{\frac{\text { chloroform }}{50^{\circ} \mathrm{C}}}{[\eta] / \mathrm{cm}^{3} \mathrm{~g}^{-1}}$} \\
\hline & \multicolumn{2}{|c|}{$40{ }^{\circ} \mathrm{C}$} & $50{ }^{\circ} \mathrm{C}$ & \\
\hline & $M_{\mathrm{w}} / 10^{4}$ & {$[\eta] / \mathrm{cm}^{3} \mathrm{~g}^{-1}$} & {$[\eta] / \mathrm{cm}^{3} \mathrm{~g}^{-1}$} & \\
\hline PCHD-1 & 1.97 & 20.2 & 19.3 & 29.4 \\
\hline PCHD-2 & 1.77 & 18.8 & 18.4 & 28.5 \\
\hline PCHD-3 & 1.22 & 15.7 & 15.1 & 22.1 \\
\hline PCHD-4 & 0.55 & 11.0 & & 13.5 \\
\hline PCHD-5 & 0.25 & 7.12 & & 8.48 \\
\hline
\end{tabular}

Table 2. Results from MALLS on PCHDs in THF

\begin{tabular}{ccccc}
\hline & $40{ }^{\circ} \mathrm{C}$ & $\begin{array}{c}10^{4} A_{2} / \\
\mathrm{mol} \mathrm{g}^{-2} \mathrm{~cm}^{3}\end{array}$ & $M_{\mathrm{w}} / 10^{4}$ & $\begin{array}{c}\frac{5{ }^{\circ} \mathrm{C}}{10^{4} A_{2} /} \\
\mathrm{mol} \mathrm{g}^{-2} \mathrm{~cm}^{3}\end{array}$ \\
\cline { 2 - 5 } & $M_{\mathrm{w}} / 10^{4}$ & -3.0 & 1.85 & -1.7 \\
PCHD-1 & 1.85 & -4.0 & & -2.6 \\
PCHD-2 & 1.71 & -3.7 & 1.18 & -2.6 \\
PCHD-3 & 1.17 & $-3.3^{a}$ & &
\end{tabular}

${ }^{a}$ Measured at $30^{\circ} \mathrm{C}$.

was calculated to be $4.5 \mathrm{~nm}$ with the Benoit and Doty equation ${ }^{17}$ for the wormlike chain model. This small value is consistent with the weak angular dependence observed in our light scattering data (discussed below). The Kuhn segment number $\lambda M_{\mathrm{w}} / M_{\mathrm{L}}$ for PCHD-1 is about $72 \pm 10$ in THF and $51 \pm 8$ in chloroform. Furthermore, the value of $[\eta]$ for each sample in THF at $50{ }^{\circ} \mathrm{C}$ is $2-5 \%$ smaller than that at $40{ }^{\circ} \mathrm{C}$, whereas the second virial coefficient $\left(A_{2}\right)$ at $50{ }^{\circ} \mathrm{C}$ is larger than that at 40 ${ }^{\circ} \mathrm{C}$, as shown in Table 1 . These results suggest that the excluded volume effect does not necessarily lead to a significant change on the persistence length. ${ }^{12}$

Light Scattering. Figure 2 is a Zimm plot for a PCHD (PCHD-3 in Table 2) in THF at $40{ }^{\circ} \mathrm{C}$. The extrapolated infinite dilution values were almost independent of $Q^{2}$, which indicates that $R_{\mathrm{g} S}$ of the current polymer samples are too small to
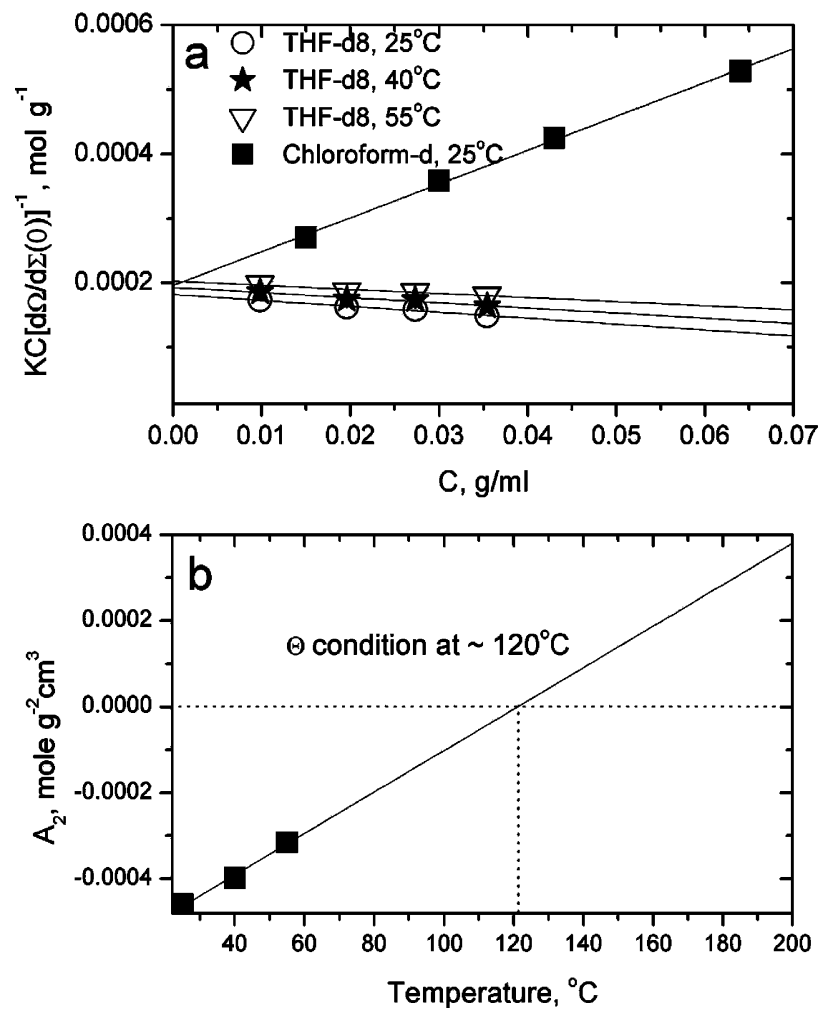

Figure 3. (a) $K C \mathrm{~d} \Omega / \mathrm{d}(\Sigma \Omega)$ vs $C$ for PCHD-6 in chloroform- $d$ at 25 ${ }^{\circ} \mathrm{C}$ and in THF- $d_{8}$ at 25,40 , and $55^{\circ} \mathrm{C}$. (b) $A_{2}$ variation with increasing temperature for PCHD-6.

determine by light scattering. The inverse scattering intensity at $Q=0$ follows a straight line having a significant negative slope. $M_{\mathrm{w}}$ and $A_{2}$ thus obtained are shown in Table 2. $A_{2}$ for PCHD- 1 and PCHD-3 in THF at $50{ }^{\circ} \mathrm{C}$ are appreciably larger than those at $40{ }^{\circ} \mathrm{C}$, although still less than zero, whereas the obtained $M_{\mathrm{w}}$ is independent of temperature as expected. These results indicate that the theta temperature is higher than $50{ }^{\circ} \mathrm{C}$. The $R_{\mathrm{g}}$ for the PCHD sample were calculated to be $23 \AA$ in $\mathrm{THF}$ and $27 \AA$ in chloroform with the Benoit and Doty equation ${ }^{17,18}$

$$
R_{\mathrm{g}}^{2}=\frac{L L_{p}}{3}-L_{p}^{2}+\frac{2 L_{p}^{3}}{L}-\frac{2 L_{p}^{4}}{L^{2}}\left[1-\exp \left(-\frac{L}{L_{p}}\right)\right]
$$

for the wormlike chain model with the parameters being $M_{L}=$ $200 \mathrm{~nm}^{-1}, \lambda^{-1}=2 L_{p}=1.3 \mathrm{~nm}$, and $M=5300$ for THF solution and $M_{L}=200 \mathrm{~nm}^{-1}, \lambda^{-1}=2 L_{p}=1.85 \mathrm{~nm}$, and $M=5300$ for chloroform solution. These values are fairly close to those determined by SANS.

Small-Angle Neutron Scattering. For a homogeneous polymer solution the methodology to extract $R_{\mathrm{g}}$ and $A_{2}$ is well established, and $R_{\mathrm{g}}$ may be derived ${ }^{10,19}$ via (Zimm) plots of $\mathrm{d} \Sigma^{-1}$ $(Q) / \mathrm{d} \Omega$ vs $Q^{2}$.

$$
\left(\frac{\mathrm{d} \Sigma(Q)}{\mathrm{d} \Omega}\right)^{-1}=\left(\frac{\mathrm{d} \Sigma(0)}{\mathrm{d} \Omega}\right)^{-1}\left[1+\frac{Q^{2} R_{\mathrm{g}}{ }^{2}}{3}+\ldots\right]
$$

$M_{\mathrm{w}}$ and $A_{2}$ may be determined from the concentration (c) dependence of $\mathrm{d} \Sigma(0) / \mathrm{d} \Omega$ by plotting $[\mathrm{d} \Sigma(0) / \mathrm{d} \Omega]^{-1}$ vs $c$

$$
\frac{K_{N} c \rho^{-2}}{\mathrm{~d} \Sigma(0, c) / \mathrm{d} \Omega}=\frac{1}{M_{\mathrm{w}}}+2 A_{2} c
$$

where $K_{N}$ is a contrast factor which is a function of the difference 

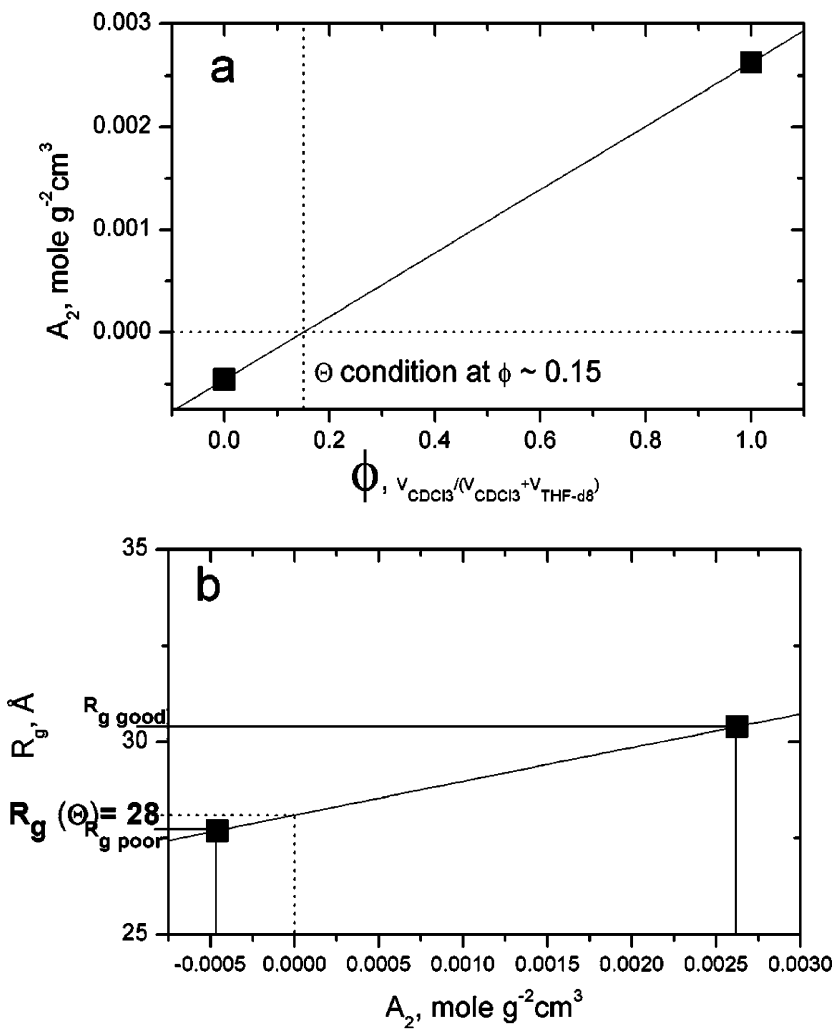

Figure 4. (a) $A_{2}$ comparison in THF- $d_{8}$ and chloroform- $d$ (b) $R_{\mathrm{g}}(C=0)$ vs $A_{2}$.

in scattering power between the solute molecules and the solvent

$$
K_{N}=\frac{N_{\mathrm{A}}}{\rho^{2}}\left(\frac{b_{1}}{v_{1}}-\frac{b_{2}}{v_{2}}\right)^{2}
$$

$N_{\mathrm{A}}$ is Avogadro's number and $b_{i}$ and $v_{i}$ are the scattering length and specific volume of a monomer of polymer $i$, respectively, and $\rho$ is the density $\left(1.07 \mathrm{~g} / \mathrm{mL}\right.$ for PCHD). ${ }^{10,19-21}$

After subtracting incoherent backgrounds, SANS data from a PCHD (PCHD-6 in Table 2) in THF- $d_{8}$ at $25^{\circ} \mathrm{C}$ are shown in Figure 3 as a function of polymer concentration and were fitted via Zimm plots (eq 6) and also to the Debye function (eq 8 ) to determine $\mathrm{d} \Sigma(0) / \mathrm{d} \Omega$ with good agreement $( \pm 5 \%)$ between the two approaches.

$$
P(Q)=\left(2 / Q^{4} R_{\mathrm{g}}^{4}\right)\left[\exp \left(-Q^{2} R_{\mathrm{g}}{ }^{2}\right)-1+Q^{2} R_{\mathrm{g}}{ }^{2}\right]
$$

The measured radii at several concentration were extrapolated to $C=0$ to obtain $R_{\mathrm{g}}(C=0)$. The $M_{\mathrm{w}}$ and $A_{2}$ values were determined from eq $6 .^{10,19}$ Typical plots of $K C[\mathrm{~d} \Sigma / \mathrm{d} \Sigma(0)]^{-1}$ vs $C$ for a PCHD (PCHD-6 in Table 2) in two different solvents are shown in Figure $3 \mathrm{a}$. The $A_{2}$ values for PCHD-6 in chloroform- $d$ are positive (Figure $3 \mathrm{a}$ ), indicating good solvent condition, while the $A_{2}$ values in THF- $d_{8}$ are negative at all temperatures, showing poor solvent quality. However, compared to the large positive slope in chloroform- $d$, the polymer in THF$d_{8}$ is close to the $\Theta$ condition. The temperature variation of $A_{2}$ (Figure 3b) suggests that the $\Theta$ condition $\left(A_{2}=0\right)$ for this polymer-solvent system might be around $120{ }^{\circ} \mathrm{C}$, which is above the boiling point $\left(\sim 65{ }^{\circ} \mathrm{C}\right)$ of $\mathrm{THF}-d_{8}$, and this is consistent with the light scattering results. The values of $A_{2}$ for PCHD-6 in mixed solvents (THF- $d_{8}+$ chloroform- $d$ ) at $25{ }^{\circ} \mathrm{C}$ are shown in Figure 4a. These data suggest that a mixed solvent with $\phi_{\mathrm{CDCl}_{3}} \sim 0.15$ may be close to the $\Theta$ conditions for PCHD-6 at $25{ }^{\circ} \mathrm{C}$. The plot of $R_{\mathrm{g}}(C=0)$ vs $A_{2}$ for PCHD-6 suggests that $R_{\mathrm{g}}$ at the $\Theta$ condition is $28 \AA$ for this particular molecule (Figure $4 b$ ).

In summary, we report here the solution properties of PCHD in THF and chloroform derived from neutron scattering, light scattering, and viscometry studies. All the results indicate that PCHD (high 1,4/1,2 ratios) is not as stiff as initially suggested. However, these molecules are unlike common flexible coil vinyl polymers such as polystyrene. Specifically, the Kuhn segment length of PCHD having high 1,4 microstructure is similar to that of polystyrene, while the bead diameter of PCHD is much smaller.

Acknowledgment. This research was supported by the Division of Material Sciences and Engineering, Office of Basic Energy Sciences, U.S. Department of Energy (DOE), under Contract DE-AC05-00OR22725 with Oak Ridge National Laboratory (ORNL), managed and operated by UT-Battelle, LLC. This research was conducted at the Center for Nanophase Materials Sciences, which is sponsored at ORNL by the Division of Scientific User Facilities, U.S. Department of Energy. We also acknowledge the use of neutron facilities at NIST, MD, and Paul Scherrer Institute Switzerland.

\section{References and Notes}

(1) Natori, I.; Imaizumi, K.; Yamagishi, H.; Kazunori, M. J. Polym. Sci. Part B: Polym. Phys. 1998, 36, 1657

(2) Nakano, Y.; Sato, K. JP 11 189,614[99 189,614] (CA;131;7468n)

(3) Naumova, S. F.; Yurina, O. D.; Flesher, A. I.; Gerasima, B. G.; Erofeev, B. V. Versti. Akad. Nauk BSSR. Ser. Khim. Nauvk 1977, (4) $5(\mathrm{CA} ; 87 ; 185414 \mathrm{a})$.

(4) David, J. L.; Gido, S. P.; Hong, K.; Zhou, J.; Mays, J. W.; Tan, N. B. Macromolecules 1999, 32, 3216.

(5) Pochan, D. J.; Gido, S. P.; Zhou, J.; Mays, J. W.; Whitmore, M.; Ryan, A. J. J. Polym. Sci., Part B: Polym. Phys. 1997, 35, 2629.

(6) Hong, K.; Mays, J. W. Macromolecules 2001, 34, 782

(7) Glinka, C.; Barker, J. G.; Hammouda, B.; Krueger, S.; Moyer, J. J.; Orts, W. J. J. Appl. Crystallogr. 1998, 31430.

(8) http://sinq.web.psi.ch/sinq/instruments.html.

(9) Wignall, G. D.; Bates, F. S. J. Appl. Crystallogr. 1987, 20, 28

(10) Wignall, G. D. In Physical Properties of Polymers, 3rd ed.; Mark, J. E., Ed.; Cambridge University Press: New York, 2004; Chapter 7, pp 424-511.

(11) Dubner, W. S.; Schultz, J. M.; Wignall, G. D. J. Appl. Crystallogr. 1990, 23, 469.

(12) Yamakawa, H. Helical Wormlike Chains in Polymer Solutions; Springer: Berlin, 1997.

(13) Norisuye, T.; Fujita, H. Polym. J. 1982, 14, 143.

(14) Einaga, Y.; Koyama, H.; Konishi, T.; Yamakawa, H. Macromolecules 1989, 22, 3419.

(15) Kuwata, M.; Murakami, H.; Norisuye, T.; Fujita, H. Macromolecules 1984, 17, 2731.

(16) Abe, F.; Einaga, Y.; Yamakawa, H. Macromolecules 1991, 24, 4423.

(17) Benoit, H.; Doty, P. J. Phys. Chem. 1953, 57, 958.

(18) Terao, K.; Terao, Y.; Teramoto, A.; Nakamura, N.; Fujiki, M.; Sato, T. Macromolecules 2001, 34, 4519.

(19) Zimm, B. H. J. Chem. Phys. 1948, 16, 157.

(20) Maconnachie, A.; Richards, R. W. Polymer 1978, 19, 739

(21) Maconnachie, A.; Kambour, R. P.; White, D. M.; Rostami, S. Walsh, D. J. Macromolecules 1984, 17, 2645.

MA052022H 